\title{
Worry over dentists and GPs taking early retirement since 2015
}

Many dentists and GPs in Scotland have taken early retirement since 2015 due to work pressure and disillusionment with the job, according to the Scottish Liberal Democrats.

The party made a Freedom of Information (FOI) request to the Scottish Government on retirement numbers and the initial data ${ }^{1}$ provided showed that 221 dentists and 541 GPs retired before reaching their state pension age between 2015 and 2018.

However, it has since been revealed that the data supplied by the Scottish Public Pensions Agency were wrong. Nevertheless, early retirement numbers were still evident.

Scottish Liberal Democrat health spokesperson Alex Cole-Hamilton MSP said the government was presiding over a system that was leaving health professionals 'exhausted and disenchanted'.

'Hundreds of GPs and dentists have left their professions before reaching their state pension age. Many doctors are exhausted and disenchanted. At every turn, the Scottish Government has mucked up workforce planning in the health service, while years of disinvestment has piled the pressure on primary care. The number of practices reporting GP vacancies has gone through the roof.

'To keep staffing levels sustainable and make medical careers attractive they need to make sure health professionals have the resources and backup they need to get the job done.

'Scottish Liberal Democrats are clear that we need to see an end to the neglect of primary care and an agreement to embed a mental health practitioner in every surgery, ending the scandal of long waits for this treatment and reducing some of the pressure on GPs. An annual report and parliamentary debate on workforce planning would also help prevent more mistakes in workforce planning.'

A Scottish Government spokesperson told the $B D J$ : 'These statistics were issued by the Scottish Public Pensions Agency based on data which turned out to be wrong.

'The correct picture is that there were only 110 early retirements by General Dental Practitioners [GDPs] between 2015 and 2018 - and not 221 as stated.

'Retirement rates by GDPs in Scotland remain very low, with just 73 dentists retiring

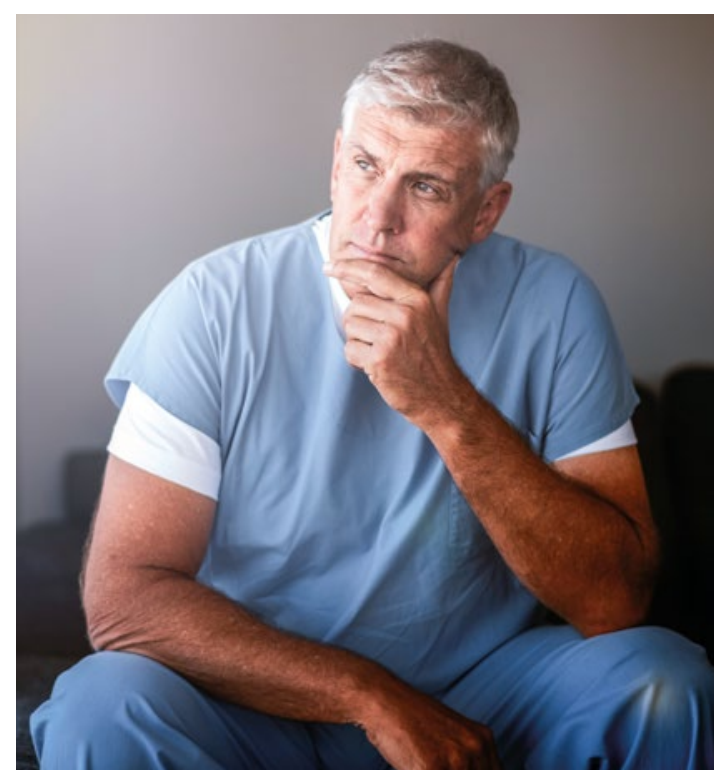

in total last year - of whom only 40 were early retirements.

'There is now a record number of dentists working in Scotland, with the total standing at 3,052 on 30 September 2018 compared to 2,261 in 2007 - an unprecedented increase of more than a third.'

The FOI details on the Scottish

Government's website will be updated soon.

\section{References}

1. Scottish Government. GPs and dentists retirement numbers and ages: FOI release. 2019. Available at https:// www.gov.scot/publications/foi-19-00620/ (accessed April 2019).

\section{Scottish practices due to produce Duty of Candour reports}

Dentists in Scotland are being reminded that their practices have to publish their Duty of Candour annual report as soon after 1 April 2019 as possible.

The purpose of the Duty of Candour procedure (https://www2.gov.scot/Topics/ Health/Policy/Duty-of-Candour) is to support implementation of consistent responses across health, social work, and social care providers when there has been an incident that has resulted in unintended or unexpected harm that is not related to the course of the condition for which the person was receiving care.

These reports should be completed by the named 'responsible person' at the practice, as set by each health board.

BDA Expert Members can access a template to help produce the annual report.
The report must contain:

- Details of the number and nature of Duty of Candour incidents which occurred in the practice that year

- An assessment of how the Duty of Candour procedures were carried out

- Information about the practice's Duty of Candour policies and procedures, including both the procedures for identifying and reporting incidents and the support available to staff and patients affected by incidents

- Information about any changes made to the above policies after a duty of candour incident occurred

- Any other information the responsible person feels is relevant.

In addition, the report must not mention any person's name nor contain any information which might identify any person.

All practices should publish the report in any appropriate way such as on its website or making it readily available within the surgery.

Once the report has been published, the provider must send it to one of two places:

- If the practice is wholly private, it must be sent to Healthcare Improvement Scotland, using the eForms system (https://hisportal.scot.nhs.uk/Account/ Login?ReturnUrl=/)

- If the practice is running an NHS or mixed practice, it should be emailed it to the Duty of Candour Lead within the practice's relevant NHS Board (https://www2.gov.scot/Topics/Health/ NHS-Workforce/NHS-Boards). 